\title{
APPLICATION OF PALSAR-2 REMOTE SENSING DATA FOR LANDSLIDE HAZARD MAPPING IN KELANTAN RIVER BASIN, PENINSULAR MALAYSIA
}

\author{
Amin Beiranvand Pour*, Mazlan Hashim \\ Geoscience and Digital Earth Centre (Geo-DEC) \\ Research Institute for Sustainability and Environment (RISE) \\ Universiti Teknologi Malaysia (UTM) \\ 81310 UTM Skudai, Johor Bahru, Malaysia \\ *Corresponding author: a.beiranvand@utm.my; mazlanhashim@utm.my
}

Commission VI, WG VI/4

KEY WORDS: PALSAR-2; Landslide hazard mapping; Kelantan River basin; Peninsular Malaysia

\begin{abstract}
:
Yearly, several landslides ensued during heavy monsoons rainfall in Kelantan river basin, peninsular Malaysia, which are obviously connected to geological structures and topographical features of the region. In this study, the recently launched Phased Array type Lband Synthetic Aperture Radar-2 (PALSAR-2) onboard the Advanced Land Observing Satellite-2 (ALOS-2), remote sensing data were used to map geological structural and topographical features in the Kelantan river basin for identification of high potential risk and susceptible zones for landslides. Adaptive Local Sigma filter was selected and applied to accomplish speckle reduction and preserving both edges and features in PALSAR-2 fine mode observation images. Different polarization images were integrated to enhance geological structures. Additionally, directional filters were applied to the PALSAR-2 Local Sigma resultant image for edge enhancement and detailed identification of linear features. Several faults, drainage patterns and lithological contact layers were identified at regional scale. In order to assess the results, fieldwork and GPS survey were conducted in the landslide affected zones in the Kelantan river basin. Results demonstrate the most of the landslides were associated with N-S, NNW-SSE and NE-SW trending faults, angulated drainage pattern and metamorphic and Quaternary units. Consequently, structural and topographical geology maps were produced for Kelantan river basin using PALSAR-2 data, which could be broadly applicable for landslide hazard mapping.
\end{abstract}

\section{INTRODUCTION}

The Advanced Land Observing Satellite-2 (ALOS-2) was launched on May 24, 2014 as successor of ALOS-1 (launched on January 24, 2006 and decommissioned in May 2011). The ALOS-2 is exclusively installed with the Phased Array type Lband Synthetic Aperture Radar-2 (PALSAR-2) using microwaves to maximized its ability compare to the ALOS-1, on which three sensors (two optical and one microwave devices) were onboard (Suzuki et al., 2012). PALSAR-2 of the ALOS-2 has been significantly improved from the ALOS-1's PALSAR in all aspects, including resolution, observation band and time lag for data provision (Suzuki et al., 2012). ALOS-2 science capabilities include global environmental monitoring using the time-series PALSAR-2. The research target also covers biospheric, cryospheric and coastal ocean research as well as disaster mitigation (Shimada, 2013). PALSAR-2 is a microwave sensor that emits L-band radio waves and receives their reflection from the ground to acquire information (Suzuki et al., 2012). It has three observation modes, including (i) Spotlight mode: the most detailed observation mode with 1 by 3 meters resolution and observation width of $25 \mathrm{~km}$; (ii) Strip map mode: a high-resolution mode with the choice of 3 (ultra fine), 6 (high sensitivity) or 10 (fine) meters resolution and observation width of 50 or $70 \mathrm{~km}$; and (iii) ScanSAR mode: a broad area observation width of 350 (nominal) or 490 (wide) $\mathrm{km}$ and resolution of 100 or 60 meters (Yamamoto et al., 2013; Shimada et al., 2015).

The wavelength of the L-band is relatively long among microwaves (C-band: about $6 \mathrm{~cm}$ and $\mathrm{X}$ - band: about $3 \mathrm{~cm}$ ), allowing it to travel all the way down to the ground through vegetation (Woodhouse, 2006, Pour and Hashim, 2014, 2015). Not only can information be, obtained about vegetation but information of the ground surface can be obtained as well. Additionally, L-band is not affected by the growth of vegetation, which is useful for SAR interference analysis (Interferometry). Therefore, L-band is capable to acquire changes on the land more precisely compared to other band's SAR when some diastrophism takes place due to an earthquake or a volcanic activity and floods or landslides caused by a natural disaster (Suzuki, 2014). The objective of this study is to identify high potential risk and susceptible zones for geological origin hazards using the recently launched ALOS-2-Phased Array type L-band Synthetic Aperture Radar-2 (PALSAR-2) remote sensing data in the Kelantan river basin at regional and district scales. 


\section{MATERIALS AND METHODS}

\subsection{Geology of the study area}

The state of Kelantan is located in north-eastern corner of Peninsular Malaysia. Kelantan river is the major river in the region. It appears at the convergence of the Galas river and Lebir river near Kuala Kari and meanders over the coastal plain until it finally degrades into the South China Sea. Kelantan river basin covers $923 \mathrm{~km}^{2}$, which is about $85 \%$ of the Kelantan state's surface area. It is composed of flat slope to moderately sloping areas in northern part and steep scraps and high slopes in the southern part of the river basin. A wide variety of rocks consisting of igneous, sedimentary and metamorphic rocks are distributed in a north-south trend in the Kelantan state. Typically, four types of rocks are classified in the region, including granitic rocks, sedimentary/metasedimentary rocks, extrusive rocks (volcanic rocks) and unconsolidated sediments (Figure 1). Localised geological features comprise faulting and jointing in the granitic rocks and folding, faulting and jointing in the sedimentary rocks. Granitic rocks are distributed in the west (the Main Range granite) and east borders (the Boundary Range granite) of the state of Kelantan (Department of Minerals and Geoscience Malaysia, 2003).

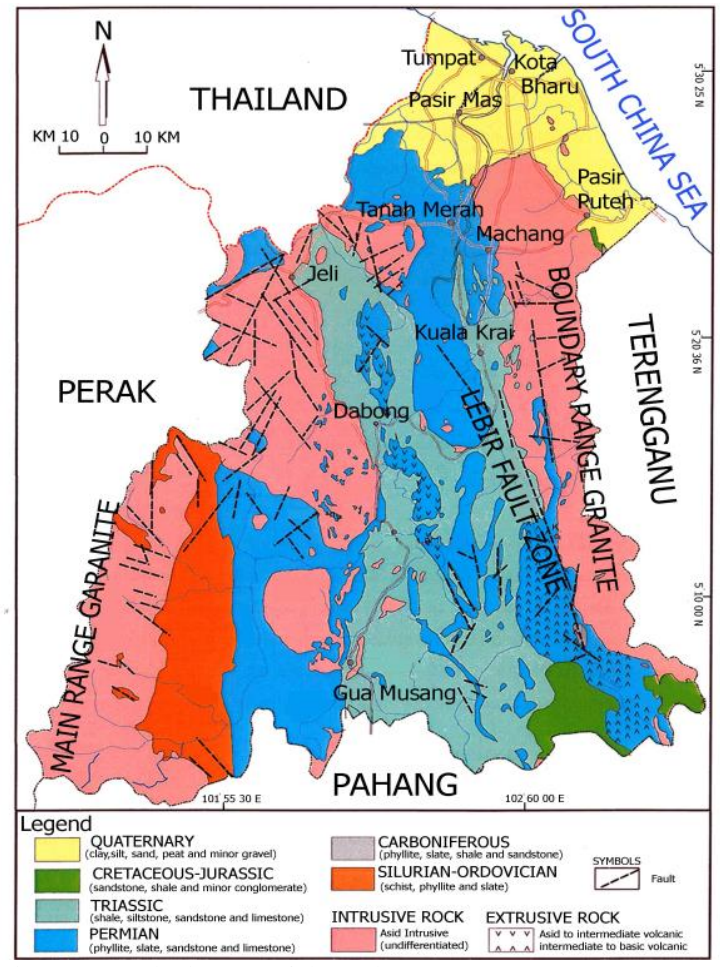

Figure 1. Geologic map of the Kelantan state.

\subsection{Remote sensing data}

In this investigation, a ScanSAR mode dual polarization (level 3.1 ) and two Fine mode dual polarization (level 3.1) PALSAR2 scenes were obtained from ALOS-2 data distribution consortium online system Remote Sensing Technology Center of Japan (RESTEC) (http://www.restec.or.jp/english/index.html) and PASCO Corporation (http://en.alos-pasco.com; https://satpf.jp/) for comprehensive analysis of major geological structures and detailed characterizations of lineaments in the state of Kelantan. The data used in this study were acquired during dry season
(June to August, 2015). The data were processed using the ENVI (Environment for Visualizing Images) version 5.2 software package.

\subsection{Data analysis}

Systematic image processing techniques were implemented to the PALSAR-2 data for geological structures and lineament mapping at both regional and district scales in the state of Kelantan. In this study, the median spatial convolution filter was used for noise removal and smoothing the PALSAR-2 images. The median filter is a particularly useful statistical filter in the spatial domain, which effectively remove speckle (salt and pepper noise) in radar images without eliminating fine details (Schowengerdt, 2007). The directional nature of geological lineaments accentuates the need for directional filtering to obtain maximum structural mapping efficacy. Edge enhancing filter highlights any changes of gradient within the image features such as structural lines. In this study, for identifying linear features in particular directions and edge enhancement in the spatial domain, directional convolution filters were applied to the median resultant image. Directional filtering technique is a straightforward method for extracting edges in the spatial domain that approximates the first derivative between two adjacent pixels. The algorithm produces the first difference of the image input in the horizontal, vertical, and diagonal directions (Jensen, 2005).

\section{RESULTS AND DISCUSSION}

A wide-swath ScanSAR observation mode of PALSAR-2 was used for comprehensive analysis of major geological structures, which shows mega-geomorphology and mega-lineaments in the Kelantan state. Figure 2 shows RGB colour-composite of $\mathrm{HH}$ polarization channel in red, HV polarization channel in green and $\mathrm{HH}+\mathrm{HV}$ polarization channel in blue for the ScanSAR median resultant image. The RGB colour-composite yields an image with great structural details and geomorphological information. The different colors in the image indicate different backscattering signals from the ground. The Main Range granites located in in the western part of the image and the Boundary Range granite in the east borders of Kelantan state appear as light green to green in colour, which shows the regions with high altitude in the scene (Fig. 2). Major transcrustal lineaments such the Bentong-Raub Suture Zone (BRSZ) and Lebir Fault Zone are also detected. Quarternary deposits, Triassic marine siliciclastics, volcaniclastics, sandstone and limestone are manifested as pink to purple tones consisting of lands with low elevation (Fig. 2). Lakes and main river systems are portrayed blue to dark blue in the image. In fact, the lines formed by blue to dark blue colour on the image are faults and fracture zones occupied by streams. Figure 4 shows ScanSAR HV polarization image that is superimposed by general topography map of the Kelantan state (Department of Minerals and Geoscience Malaysia, 2003). It is evident that the morphology of the study area is largely controlled by rock type and structure. High elevation areas $(500-100 \mathrm{~m}$ and $<1000 \mathrm{~m}$ ) in the Kelantan state are mountainous areas associated with Main Range granites (in the west) and Boundary Range granite (in the east), which are detected as green to light green colour in the Figure 3. Hilly, plain and coastal areas with altitude between 500 to $50 \mathrm{~m}$ are associated with sedimentary rocks, which are manifested pink to purple colour in the Figure 3. 


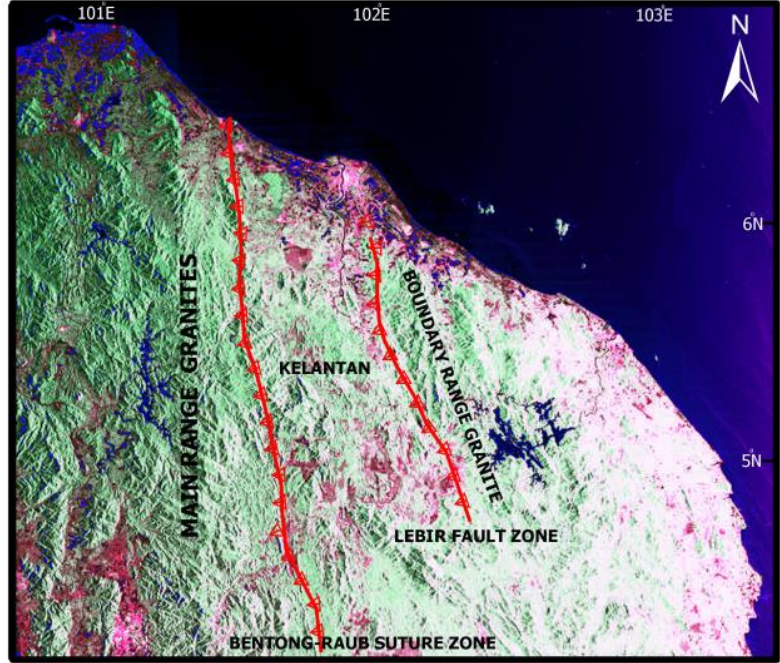

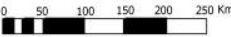

Figure 2. RGB colour combination ( $\mathrm{HH}, \mathrm{HV}$ and $\mathrm{HH}+\mathrm{HV}$ polarization channels) of PALSAR-2 Scan SAR scene covering northern part of the Peninsular Malaysia.

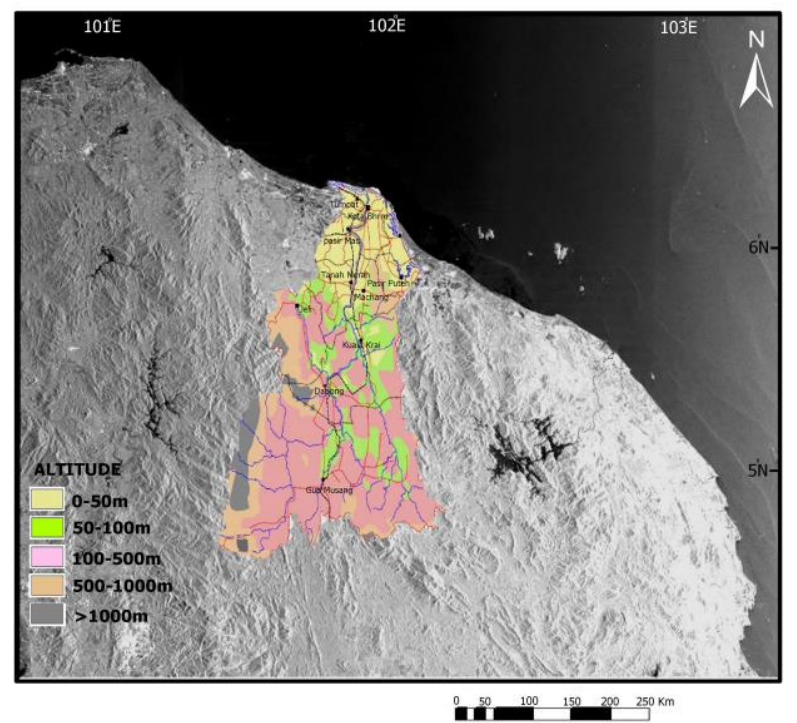

Figure 3. ScanSAR HV polarization image of the Kelantan state superimposed by general topography map.

Four directionally filtered images of fine mode observation, which contain enhanced information for set of lineaments in $\mathrm{N}$ S, E-W, NE-SW and NW-SE direction, were used for lineament mapping in the Kelantan state. Figure 4 shows structural map for the Kelantan state, which is derived from the resultant image of directional filtering to $\mathrm{HV}$ polarization channel. The most important structural features in the image map are fault zones, river systems and drainage lines patterns (Fig. 4). Within the study area two large fault zones are presented, which are the BRSZ in the north-west and Lebir Fault Zone in the south-east. The N-S, NE-SW and NNE-SSW lineament trends are commonly dominant in the image map. The dominant lineaments tend to run in the N-S direction, which is mainly linked to the N-S trending of the BRSZ (in the west) and Lebir Fault Zone (in the east). Additionally, few short NW-SE trending lineaments are detected in the western and eastern parts of the study area (Fig. 4). The N-S and NE-SW striking system distributed in the south eastern segment of the region is particularly related to Lebir Fault Zone. Pattern of the lineament map in north-western part of the image map displays the occurrence of BRSZ fault zone, which contains lineaments in $\mathrm{N}-\mathrm{S}$ and NNE-SSW directions. Most of the short and smaller faults follow the N-S, NE-SW and NNE-SSW trends as the major fault systems in the Kelantan state. It seems that the NWSE faults are the youngest faults in the study area due to low frequency of lineaments in this trend. The rivers in the study area are structurally controlled. They display zigzag patterns due to the presence of fractures, joints and faults with changes in orientation. The drainage system in the Kelantan river basin shows dendritic, sub-dendritic and rectangular patterns (Fig. 4).

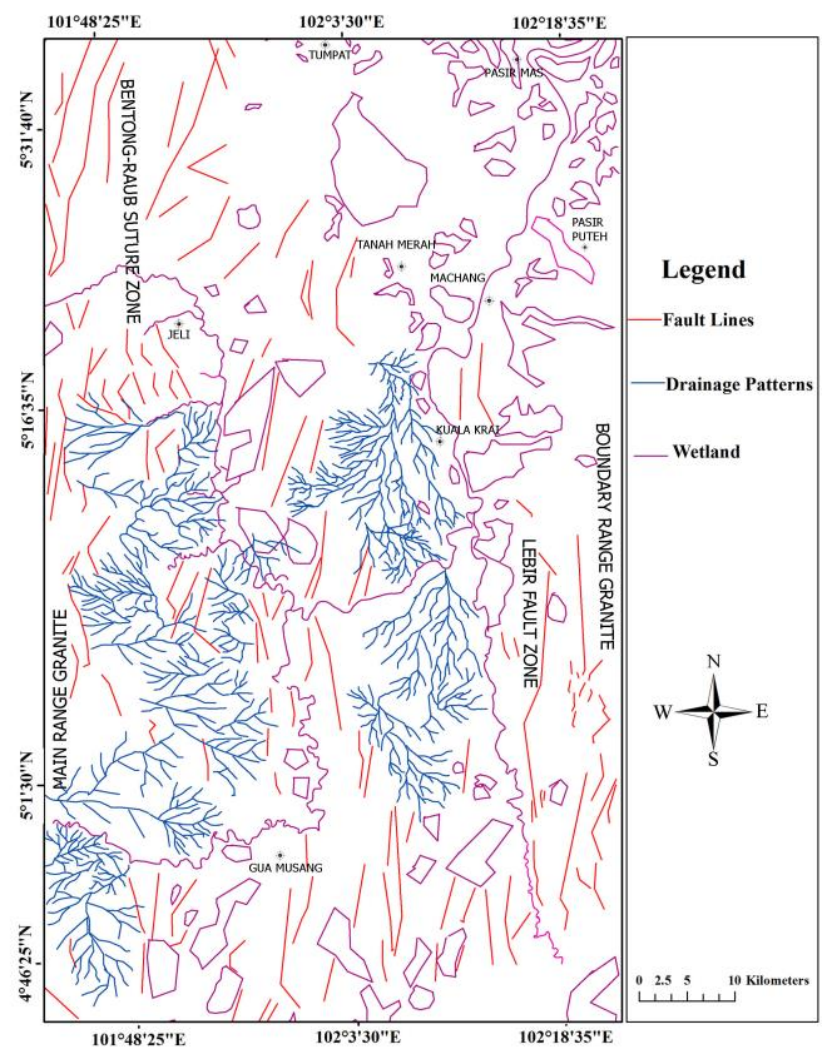

Figure 4. Structural lineament map of the Kelantan state derived from directional filtering to $\mathrm{HV}$ polarization channel.

\section{CONCLUSIONS}

Results of this investigation indicate that the PALSAR-2 onboard the ALOS-2 has proven to be successful advanced remote sensing satellite data for disasters monitoring in tropical environments. Analysis of the PALSAR-2 data provided significant information for identifying high potential risk and susceptible zones for natural hazards of geological origin in the Kelantan river basin, Malaysia. Landslide recurrence regions were detected in high-altitude segment of south and southwestern part of the Kelantan state, which is dominated with high density of rectangular drainage pattern and topographic slope of metamorphic and Quaternary rock units. Some of the large landslide zones were associated with N-S, NNE-SSW and NESW trending fault systems. 


\section{REFERENCES}

Department of Minerals and Geoscience Malaysia (2003). Quarry Resource Planning for the State of Kelantan. Osborne and Chappel Sdn. Bhd.

Jensen, J.R. (2005). Introductory Digital Image Processing: A remote sensing perspective. Pearson Prentice Hall, Upper Saddle River NJ 07458. Third edition, p: 276-287.

Pour, A.B., Hashim, M., 2015 Structural mapping using PALSAR data in the Central Gold Belt Peninsular Malaysia, Ore Geology Reviews, vol.64, pp. 13-22.

Pour, A.B., Hashim, M., 2014. Structural geology mapping using PALSAR data in the Bau gold mining district, Sarawak, Malaysia, Adv. Space Research, vol.54 (4), pp. 644-654,

Schowengert, R.A.m, 2007. Remote sensing: models and methods for image processing," 3rd ed, Burlington, M.A, Academic Press, Elsevier. pp. 229-243.

Shimada, M. (2013). ALOS-2 science program. Proceedings of IGARSS (IEEE international Geoscience and Remote Sensing symposium), Melbourne, Australia, July 21-26, 2013.

Shimada, M., Watanabe, M., Motooka, T., Kankaku, Y., Suzuki, S. (2015). Calibration and validation of the PALSAR-2. Proceedings of the IGARSS (International Geoscience and Remote Sensing Symposium) 2015, Milan, Italy, July 26-31, 2015.

Suzuki, S., Kankaku Y., Imai, H., Osawa Y. (2012). "Overview of ALOS-2 and ALOS-3", Proceedings of SPIE,' Earth Observing Missions and Sensors: Development, Implementation, and Characterization II,' Vol. 8528, Kyoto, Japan, October 29, 2012, 852811 (November 9, 2012); doi: $10.1117 / 12.979184$

Suzuki, S. (2014). "Advanced Land Observing Satellite-2 "DAICHI-2" (ALOS-2) - Mission talk by team leaders," JAXA, May 2014

URL: http://global.jaxa.jp/projects/sat/alos2/leaders.html

Woodhouse, I.H. (2006). Introduction to microwave remote sensing. CRC Press, Taylor \& Francis Group, Boca Raton.

Yamamoto, T., Kawano, I., Iwata, T., Arikawa, Y., Itoh, H., Yamamoto, M., Nakajima, K. (2013). Autonomous Precision Orbit Control of ALOS-2 for Repeat-Pass SAR Interferometry. Proceedings of IGARSS (IEEE International Geoscience and 